\title{
Human-itarian aid? Two forms of dehumanization and willingness to help after natural disasters
}

\author{
Luca Andrighetto '*, Cristina Baldissarri ${ }^{2}$, Sara Lattanzio ${ }^{2}$, Steve \\ Loughnan $^{3}$ and Chiara Volpato ${ }^{2}$ \\ 'University of Genova, Italy \\ ${ }^{2}$ University of Milano-Bicocca, Milan, Italy \\ ${ }^{3}$ University of Melbourne, Australia
}

\begin{abstract}
The present research explores the distinct effects of animalistic and mechanistic dehumanization on willingness to help natural disaster victims. We examined Japanese and Haitians, two national groups recently struck by earthquakes. We showed that Italian participants differently dehumanized the two outgroups: Japanese were attributed low human nature (dehumanized as automata), whereas Haitians were attributed low human uniqueness (dehumanized as animal-like). Ninety participants were then randomly assigned to the Japanese or Haitian target group condition. Mediation analyses showed that animalistic dehumanization decreased willingness to help Haitians, whereas mechanistic dehumanization decreased willingness to help Japanese, even when controlling for attitudes. Importantly, reduced empathy explained the effects of both forms of dehumanization on intergroup helping.
\end{abstract}

Extraordinary natural disasters often elicit extraordinary acts of helping. In the face of hurricanes, earthquakes, tsunamis, or volcanic eruptions, people around the world give generously to assist strangers in distant lands. However, recent history has shown us that there is considerable variability in helping following natural disasters. For example, foreign donations to assist victims of the Indian Ocean Tsunami amounted to $\$ 1249.80$ per victim, whereas the world donated only $\$ 16.36$ per victim after the Pakistani floods, despite the UN declaring the Pakistani flooding one of the worst natural disasters of recent decades (Fisher, 2010). Although media (Brown \& Minty, 2008) and the wealth of the victim nation (Fisher, 2010) undoubtedly play a crucial role, there may be more a psychological explanation of this variability in helping behaviour.

Considerable research has investigated the psychological factors motivating people to help others (see Penner, Dovidio, Piliavin, \& Schroeder, 2005 for review). For example, dispositional factors (e.g., sympathy; Knight, Johnson, Carlo, \& Eisenberg, 1994), emotions (e.g., sense of guilt; Hibbert, Smith, Davies, \& Ireland, 2007), and the desire to maintain a positive self-image (Hopkins et al., 2007) have all been shown to affect pro-social behaviours. For real-life disasters, Zagefka and colleagues identified several variables influencing people's decision to help outgroup victims, including perceived victim blame, attributions of self-help (Zagefka, Noor, Brown, de Moura, \&

*Correspondence should be addressed to Luca Andrighetto, Università di Genova, DISFOR, Corso Podestà 2, I6 I 28, Genova, Italy (email: luca.andrighetto@unige.it). 
Hopthrow, 2011), and knowledge of the disaster areas (Zagefka, Noor, Brown, Hopthrow, \& de Moura, 2012). However, a growing body of literature shows that intergroup biases play an important role in helping in emergency contexts (Nadler, 2002; van Leeuwen \& Täuber, 2011). Several studies have shown that group membership affects pro-social behaviours: People are more willing to help ingroup members than outgroup members (Dovidio, Piliavin, Schroeder, \& Penner, 2006; Levine, Prosser, Evans, \& Reicher, 2005). Beyond mere group membership, many group-level factors shape peoples' intentions to help outgroup victims. For example, van Leeuwen (2007) revealed that perceived national identity threat increased Dutch aid to the victims of the 2004 Indian Ocean Tsunami. Further, Sun, Zagefka, and Goodwin (2013) showed that endorsing a stereotypical view of Japan predicted Chinese respondents' emotions (e.g., admiration, contempt) towards Japanese and, in turn, their concern for the victims of the 2011 Japanese Earthquake.

All these studies show that intergroup biases can play an important role in intergroup helping. In the present research we explored the impact of a recently identified intergroup bias, dehumanization. Specifically, we focused on the impact of distinct forms of dehumanization on willingness to help outgroups harmed by natural disasters. We additionally aimed to shed light on the mechanisms underlying the relationship between dehumanization and willingness to help, by exploring the mediating role of empathy.

\section{Two senses of humanness and two forms of dehumanization}

Inspired by work on infra-humanization (Leyens, Demoulin, Vaes, Gaunt, \& Paladino, 2007; Vaes, Leyens, Paladino, \& Miranda, 2012 for reviews), recent research has examined the role that dehumanization plays within intergroup contexts (Capozza, Andrighetto, Di Bernardo, \& Falvo, 2012; Viki et al., 2006). In particular, Haslam and colleagues (Haslam, 2006; Haslam \& Loughnan, 2014; Haslam, Loughnan, Kashima, \& Bain, 2008) argued that humanness has two distinct senses: Human uniqueness (HU) captures the boundary between humans and animals (e.g., rationality, morality), and human nature (HN) captures the essence of being human (e.g., warmth, emotionality). The denial of these two senses of humanness corresponds to distinct forms of dehumanization: Social groups can lack HU and thus be likened to animals, or they could lack $\mathrm{HN}$ and thus be likened to automata. The association of social groups with animals or automata is a common phenomenon, independent of outgroup attitudes and primarily based on stereotypical beliefs (Loughnan \& Haslam, 2007; Loughnan, Haslam, Sutton, \& Spencer, 2014; Saminaden, Loughnan, \& Haslam, 2010). For example, a cross-cultural study (Bain, Park, Kwok, \& Haslam, 2009) revealed that the two forms of dehumanization can reflect stereotypes: In particular, the cultural stereotype of Chinese, portraying them as having high self-control, low warmth, and high intelligence, led Anglo-Australians to deny them $\mathrm{HN}$ and to subtly associate them with automata. Our study is designed to examine whether the two forms of dehumanization (i.e., animalistic and mechanistic) would also have detrimental consequences for intergroup helping, above and beyond previously identified intergroup biases.

Some work has hinted at the possibility that outgroup dehumanization hinders people's willingness to help (Cheung \& Chan, 2000; Cuddy, Rock, \& Norton, 2007; Kemmelmeier, Broadus, \& Padilla, 2008). In particular, Cuddy et al. (2007) noted that willingness to help victims is affected by dehumanization. In their investigation conducted 2 weeks after Hurricane Katrina, they observed that for both White and 
non-White Americans, the reluctance to attribute uniquely human emotions (e.g., anguish, grief) to outgroup members reduced intentions to volunteer time to help outgroup victims. Although this study provides first evidence that dehumanization plays a role in helping after a disaster, several important questions remain unanswered. First, Cuddy and colleagues demonstrated a link between the denial of HU (infra-humanization) and reduced helping, but left unexplored the consequences of the denial of HN. Thus, it is unclear whether reduced helping is a characteristic of dehumanization in general, or rather specific to denial of HU. In the present research, we explore whether both the denial of HN (i.e., mechanistic dehumanization) and HU (i.e., animalistic dehumanization) may negatively affect willingness to help. Theorizing and research on dehumanization have typically investigated the impact of the type of humanness denied to the target, rather than the type of humanness which is retained. For example, it is the denial of HN to others which make them appear as automata, rather than the presence of HU (Haslam, 2006). Therefore, we focused on the specific type of humanness denied to each group as the relevant factor in predicting willingness to help.

Further, it is currently unclear why dehumanization is linked to reduced helping behaviour. Examining how the denial of humanity is translated into a reduced willingness to help represents an important step in understanding the impact of dehumanization. In this work, we proposed empathy for the victim as a key mechanism underlying the relation between both forms of dehumanization and helping. Indeed, empathy towards outgroup members facilitates intergroup helping (Batson, 1998; Batson \& Ahmad, 2001; Batson, Chang, Orr, \& Rowland, 2002; Stephan \& Finlay, 1999). Further, previous study revealed that victim dehumanization leads to lower levels of empathy and caring for outgroup's plight (Čehajić, Brown, \& Gonzalez, 2009), thus suggesting that dehumanization might stifle helping behaviour by reducing experienced empathy for victim suffering.

\section{The present research}

In this research, we considered two groups struck by devastating earthquakes: Haitians and Japanese. We focused on these outgroups for two reasons: These events are recent and the social and economic consequences still pervade the two communities; from a psychosocial perspective, we expected that the two groups would be subject to different forms of dehumanization. Specifically, we assumed that Haitians would be attributed less HU and thus subtly dehumanized in an animalistic way. Recent work by Vaes and Paladino (2010) supports this expectation. Based on the stereotype content model (Fiske, Cuddy, \& Glick, 2007), they showed that Italians dehumanized different national outgroups to some degree, but that these effects varied according to the uniquely human content of stereotypes ascribed to these groups. In particular, the denial of humanness to Cubans - like Haitians a Caribbean group with a sizeable African diaspora - was conveyed by stereotyping them as lacking the HU related dimension of competence. Instead, we hypothesized that Japanese would be attributed less $\mathrm{HN}$ and thus subtly dehumanized in a mechanistic way. Supporting this hypothesis, Bain et al. (2009) reported that European Australians perceived Asians (i.e., Chinese, Japanese) as lacking HN traits (Park, Haslam, Shimizu, Kashima, \& Uchida, 2013). Together, these previous findings led us to expect that the attribution of $\mathrm{HU}$ and $\mathrm{HN}$ traits to Haitians and Japanese would be complementary, with the HU dimension denied to Haitians and the HN dimension denied to Japanese (for similar results with Australian and Chinese groups see Bain et al., 2009). 
If people care less about those they see as less human, then being seen as lacking either $\mathrm{HN}$ or HU should result in lower willingness to help dehumanized outgroups. Specifically, animalistic dehumanization (i.e., the denial of $\mathrm{HU}$ ) would decrease the Italians' willingness to help Haitian victims, whereas mechanistic dehumanization (i.e., the denial of $\mathrm{HN}$ ) would decrease the Italians' willingness to help Japanese victims. By contrast, since we do not expect Haitians to be denied HN or Japanese to be denied HU, we do not expect that these retained dimensions play a role in predicting helping intentions. Stated otherwise, helping intentions will be driven by the sense of humanness the group lacks, not the humanness it retains. Crucially, for each group we expected that dehumanization would affect helping independent of outgroup attitudes. Lastly, we expected that decreased empathic feelings would mediate the relationship between dehumanization and willingness to help.

\section{Method}

\section{Preliminary study}

We conducted a preliminary study to verify the dehumanization of Haitians and Japanese. Consistent with previous research (Vaes \& Paladino, 2010), we hypothesized that Haitians would be seen as lacking HU, whereas Japanese would lack HN. Fifty-four Italians ( 50 females; $M_{\text {age }}=21.41, S D=3.18$ ) indicated whether they perceived $14 \mathrm{HU}$ traits (e.g., rational, cold) and $14 \mathrm{HN}$ traits (e.g., warmth, impulsive) as typical of Haitians and Japanese $(1=$ not at all typical; $7=$ extremely typical). The selected traits were previously validated (Bain et al., 2009; Haslam, Bain, Douge, Lee, \& Bastian, 2005; Haslam \& Bain, 2007), matched for valence, and randomly ordered. The order of presentation of the two groups was counterbalanced. A 2 (Target group: Haitians, Japanese) $\times 2$ (Trait type: HU, HN) within-subjects ANOVA revealed a main effect of Target group, $F(1,53)=5.62, p=.02, \eta_{p}^{2}=.10$, and Trait type, $F(1,53)=12.58$, $p<.001, \eta_{p}^{2}=.19$. These main effects were qualified by the predicted Target group $\times$ Trait type interaction, $F(1,53)=93.34, p<.001, \eta_{p}^{2}=.64$. As expected, simple effects analyses showed that participants perceived HU traits as more typical of Japanese $(M=4.76, S D=0.73)$ than Haitians $(M=3.52, S D=0.64), F(1,53)=73.94$, $p<.001, \eta_{p}^{2}=.58$. Conversely, HN traits were attributed more to Haitians $(M=4.25$, $S D=0.75)$ than Japanese $(M=3.49, S D=0.70), F(1,53)=27.84, p<.001, \eta_{p}^{2}=.34$. Within the groups, respondents attributed more $\mathrm{HN}$ than $\mathrm{HU}$ traits to Haitians, $F(1,53)=36.96, p<.001, \eta_{p}^{2}=.41$, whereas they attributed more HU than HN traits to Japanese, $F(1,53)=84.42, p<.001, \eta_{p}^{2}=.61$. As further confirmation of our expectations, a series of one-sample $t$-test also revealed that Haitians were perceived as lacking HU traits and the Japanese as lacking HN traits, with both ratings significantly below the neutral midpoint of the scale $(4), t(53)=5.41, p<.001$ for Haitians' HU traits, $t(53)=5.33, p<.001$ for Japanese's HN traits. In short, the outgroups lacked the predicted sense of humanness relative to the other group, the other sense of humanness, and the scale midpoint.

\section{Main study}

Participants and design

Participants were 90 undergraduate students (77 female; $\left.M_{\text {age }}=21.11 ; S D=2.49\right)$ at a large Italian university. They were randomly assigned to the Haitian $(n=47)$ or Japanese $(n=43)$ condition. 
Procedure and measures

Data were collected in April 2012, approximately 2 years after the Haitian earthquake and 1 year after the Japanese earthquake. Participants volunteered for a study focusing on 'perceptions regarding different national groups' and completed two questionnaires. The first measured the two forms of dehumanization and outgroup attitudes. Animalistic debumanization ( $\alpha=.82$ ) was assessed using seven items (e.g., 'Some aspects of Haitian [Japanese] life are typical of a backward culture') proposed by Leidner, Castano, Zaiser, and Giner-Sorolla (2010). Mechanistic debumanization $(\alpha=.83)$ was measured using eight items (e.g., 'Haitians [Japanese] are cold'; 'Haitians [Japanese] are rational') derived from Bastian and Haslam (2010). Finally, outgroup attitudes were measured by employing a feeling thermometer (Haddock, Zanna, \& Esses, 1993).

The second questionnaire was administered 1 week following the first, helping avoid demand characteristics. The dramatic consequences of the earthquake for the respective outgroup were initially made salient through a brief essay. Then, empathy was measured with six items $(\alpha=.89)$, aiming to capture the emotional empathic experience of being moved by Haitian [Japanese] suffering (e.g., 'I'm touched when thinking about the Haitian [Japanese] situation'). Afterwards, willingness to belp was measured using nine items $(\alpha=.86$; Leach, Iyer, \& Pedersen, 2007; Saguy, Chernyak-Hai, Andrighetto, \& Bryson, 2013), assessing respondents' willingness to engage in actions that would improve the condition of outgroup members (e.g., 'Signing a petition for drawing the attention of the Italian government towards the situation of Haitians [Japanese]'). Finally, participants answered demographic questions, were thanked, and debriefed. All scales ranged from 1 (completely disagree) to 7 (completely agree), except the feeling thermometer $(1$ = extremely negative $; 100=$ extremely positive $)$.

\section{Results}

Table 1 presents means and standard deviations for each variable by target group condition. Correlations between the composite variables for Haitians and Japanese condition are reported in Tables 2 and 3, respectively. To examine our predictions, we tested two mediation models for each target group by using Hayes' (2012) PROCESS macro. In both models, we entered the two forms of dehumanization as independent variables, empathy as mediator and willingness to help as dependent variable, with outgroup attitudes entered as covariate.

Table I. Means and standard deviations for each composite variable by target group condition

\begin{tabular}{lcc}
\hline & \multicolumn{2}{c}{ Target group } \\
\cline { 2 - 3 } Variables & Haitians & Japanese \\
\hline Animalistic dehumanization & $3.8 \mathrm{I}_{\mathrm{a}}(0.88)$ & $2.76_{\mathrm{b}}(1.00)$ \\
Mechanistic dehumanization & $2.94_{\mathrm{a}}(0.76)$ & $4.17_{\mathrm{b}}(0.85)$ \\
Outgroup attitudes & $58.70_{\mathrm{a}}(16.14)$ & $61.25_{\mathrm{a}}(20.18)$ \\
Empathy & $4.60_{\mathrm{a}}(1.16)$ & $3.95_{\mathrm{b}}(1.26)$ \\
Willingness to help & $4.29_{\mathrm{a}}(1.0 \mathrm{I})$ & $3.45_{\mathrm{b}}(1.19)$ \\
\hline
\end{tabular}

Note. Values with different subscripts in the same row are significantly different at $p<.02$. Standard deviations are provided in parentheses. 
Table 2. Correlations between composite variables. Haitian target group condition

\begin{tabular}{lllll}
\hline Variables & $\mathrm{I}$ & 2 & 3 & 4 \\
\hline I. Animalistic dehumanization & - & & & \\
2. Mechanistic dehumanization & $.4 \mathrm{I}^{* *}$ & - & & \\
3. Outgroup attitudes & $-.5 \mathrm{I}^{* * *}$ & $-.49^{* * *}$ & - & \\
4. Empathy & $-.34^{*}$ & -.14 & .14 & - \\
5. Willingness to help & $-.44^{* *}$ & -.19 & $.38^{* *}$ & $.56^{* * *}$ \\
\hline
\end{tabular}

Note. ${ }^{*} p \leq .05 ; * * p \leq .01 ; * * p \leq .001$.

Table 3. Correlations between composite variables. Japanese target group condition

\begin{tabular}{llllll}
\hline Variables & $\mathrm{I}$ & 2 & 3 & 4 & 5 \\
\hline I. Animalistic dehumanization & - & & & & \\
2. Mechanistic dehumanization & .18 & - & & \\
3. Outgroup attitudes & $-.39 *$ & -.12 & - & .21 & - \\
4. Empathy & -.16 & $-.43^{* *}$ & .25 & $.66^{* * *}$ & - \\
5. Willingness to help & -.26 & $-.4 I^{*}$ & .25
\end{tabular}

Note. ${ }^{*} p \leq .05 ; * * p \leq .01 ; * * p \leq .001$.

\section{Haitians target group condition}

As hypothesized, animalistic dehumanization predicted lower levels of empathy, $b=-.46, S E=.22, t(42)=2.06, p=.04$, and reduced willingness to help Haitians, $b=-.40, S E=.18, t(42)=2.18, p=.03$. By contrast, mechanistic dehumanization did not predict empathy, $b=-.01, S E=.26, t(42)=0.04, p=.96$, nor willingness to help, $b=.09, S E=.21, t(42)=0.44, p=.71$. Further, the interaction between the two forms of dehumanization did not show significant effects, $b \mathrm{~s}<|.09|, t \mathrm{~s}(41)<0.35, p s>.73$. In turn, empathy increased willingness to help, $b=.41, S E=.11, t(42)=3.72, p<.001$. Supportive to our mediation hypothesis, the effect of animalistic dehumanization on

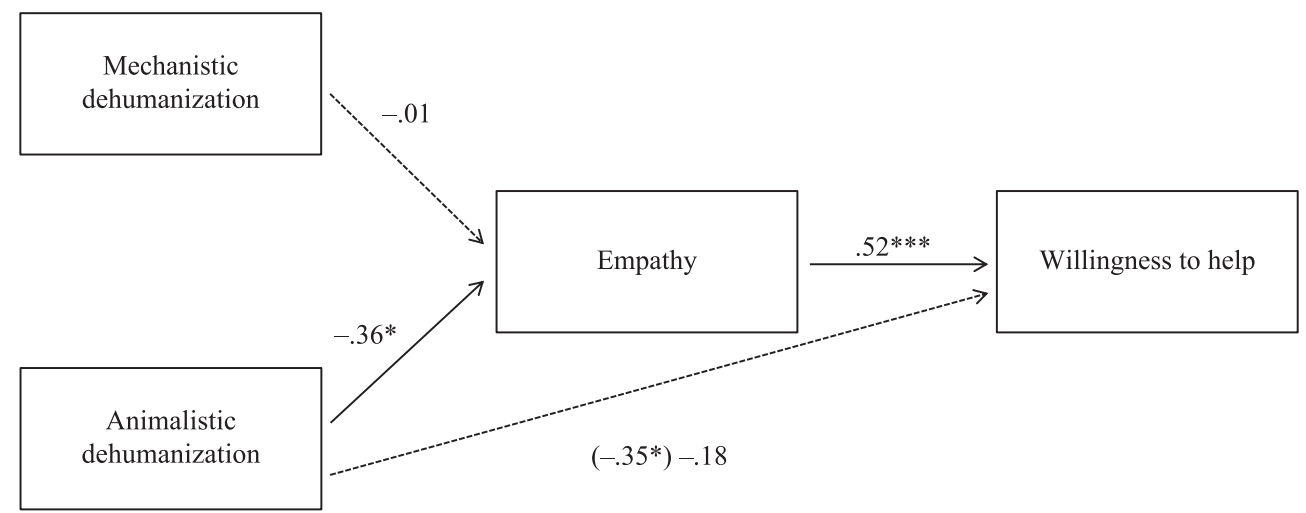

Figure I. The effect of animalistic dehumanization on willingness to help via empathy for Haitian outgroup.

Note. Outgroup attitudes were entered as covariate, $*_{p}<.05 ; * * * p<.001$. 
willingness to help turned non-significant after that empathy was entered into the model, $b=-.21, S E=.17, t(42)=1.24, p=.22$, such that the indirect path from animalistic dehumanization to intergroup helping through empathy was significant, $a * b=-.19$, $95 \%$ CI $[-0.511,-0.029]$. Crucially, this mediation model (Figure 1) remained significant after controlling for outgroup attitudes, which did not affect either empathy nor willingness to help, $b \mathrm{~s}<.01, t \mathrm{~s}(42)<1.41, p \mathrm{~s}>.16$.

\section{Japanese target group condition}

Consistent with our hypotheses, mechanistic dehumanization decreased empathy towards Japanese victims, $b=-.64, S E=.25, t(33)=-2.58, p=.01$, and willingness to help them, $b=-.55, S E=.23, t(33)=2.34, p=.03$. By contrast, animalistic dehumanization did not significantly decrease empathy, $b=-.04, \quad S E=.23$, $t(33)=0.16, p=.87$, nor willingness to help, $b=-.18, S E=.21, t(33)=0.82$, $p=.41$. The effects of the interaction between the two forms of dehumanization also did not reach significance, $b \mathrm{~s}<|.06|, t \mathrm{~s}(32)<0.24, p s>.81$. Importantly, empathy increased willingness to help, $b=.54, S E=.14, t(33)=3.96, p<.001$. The mediation hypothesis was also confirmed (Figure 2): The effect of mechanistic dehumanization on willingness to help was non-significant after that empathy was entered into the model, $b=-.20, S E=.21, t(42)=0.95, p=.35$, and the indirect path from mechanistic dehumanization to willingness to help through empathy was significant, $a^{*} b=-.35$, 95\% CI $[-0.706,-0.084]$. This mediation remained significant after controlling for attitudes towards Japanese, which did not significantly impact on our dependent variables, $b \mathrm{~s}<.01, \mathrm{ts}(33)<0.92, p \mathrm{~s}>.36 .^{1}$

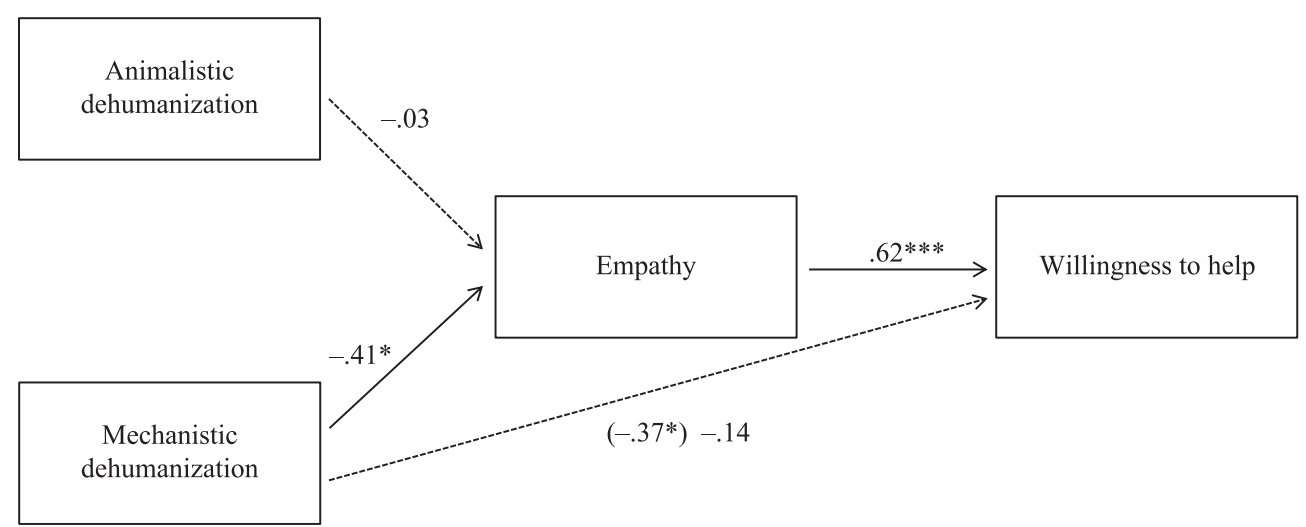

Figure 2. The effect of mechanistic dehumanization on willingness to help via empathy for Japanese outgroup.

Note. Outgroup attitudes were entered as covariate, ${ }^{*} p<.05 ; * * p<.001$.

\footnotetext{
' Given the cross-sectional nature of our data, we also tested two additional mediational models, one for each target group condition. In these models, empathy was entered as the predictor variable, the two forms of dehumanization as the mediators and willingness to help as the dependent variable, with outgroup attitudes were entered as a covariate. Neither for the Haitian target group condition $(\mathrm{a} * \mathrm{~b}=-.05,95 \% \mathrm{Cl}[-0.060,0.286])$ nor for the Japanese target group condition $(\mathrm{a} * \mathrm{~b}=.04,95 \% \mathrm{Cl}$ $[-0.011,0.166])$ the relevant form of dehumanization emerged as a reliable mediator, thus excluding the possibility that dehumanization mediates the relationship between empathy and willingness to help. Stated otherwise, the 'reverse mediation' model was not significant.
} 


\section{Discussion}

The findings offer support for our hypotheses. Dehumanizing perceptions substantially decreased empathy towards victims, which in turn reduced willingness to help them. However, differential attributions of $\mathrm{HU}$ and $\mathrm{HN}$ to outgroup members reflected distinct forms of dehumanization, which in turn distinctly impacted on willingness to help outgroup victims. More clearly, animalistic - but not mechanistic - dehumanization negatively predicted empathy and, in turn, willingness to help outgroup members who were perceived as lacking of HU (i.e., Haitians). By contrast, mechanistic - but not animalistic - dehumanization led to decreased willingness to help by reducing empathy when outgroup members were perceived as lacking $\mathrm{HN}$ (i.e., Japanese). The null effects of the interaction between $\mathrm{HN}$ and $\mathrm{HU}$ provides further evidence that the effects of dehumanization are primarily located around the dimension that is denied to the group and do not involve the dimension of humanness that the group retains. Across analyses including the retained dimension as both an independent factor and a component of an interaction, it failed to emerge as a significant predictor of either empathy or willingness to help. In short, these effects appear specific to the extent to which people dehumanize the outgroup, even though the nature of that dehumanization is sensitive to the specific group. Importantly, these effects were held when outgroup attitudes were controlled, thus dissociating dehumanization from dislike.

Although there is renewed awareness that group processes are crucial in helping behaviours within real-life disaster contexts (Michel, 2007), few studies have systematically investigated this issue. Extending on infra-humanization research (Cuddy et al., 2007), we revealed that dehumanization has an important role in individuals' willingness to help outgroups. Further, our work extends the burgeoning literature on Haslam's model of dehumanization (Haslam, 2006; Haslam \& Loughnan, 2014). To date, a number of studies (Bain et al., 2009; Loughnan \& Haslam, 2007; Saminaden et al., 2010) investigated the implicit or explicit association of different social groups with HU and HN and their consequent likening with animals or automata. However, although several studies have shown the impact of animalistic dehumanization (Bandura, Underwood, \& Fromson, 1975; Leidner et al., 2010; Zebel, Zimmermann, Viki, \& Doosje, 2008), little research has examined the consequences of mechanistic dehumanization. Recently, Leidner, Castano, and Ginges (2013) investigated the role of outgroup sentience - an aspect of mechanistic dehumanization - on intergroup conflicts. However, their study considered mechanistic dehumanization as antecedent of antisocial behaviour, whereas our focus was on mechanistic dehumanization as inhibitor of pro-social behaviour. Clearly, examining the impact of mechanistic dehumanization on intergroup relations is an important topic for future research.

Although reduced helping to Japanese and Haitian groups operated through different types of dehumanization, they shared a common mediator: Reduced empathy. It is established that we tend not to empathize with dehumanized outgroups (Čehajić et al., 2009), indicating that we do not care as deeply about the suffering of those we dehumanize (Loughnan, Pina, Vasquez, \& Puvia, 2013; Riva \& Andrighetto, 2012). The finding that empathy mediates the effect of two forms of dehumanization provides an important insight into how dehumanization may translate into impaired intergroup relations. Further, it provides at least one point of intervention to break the link between dehumanization and reduced willingness to help. 
There are a few noteworthy limitations to the present work that should guide future research. First, although the causal link between dehumanization and willingness to help is plausible and consistent with previous literature (cf. Čehajić et al., 2009; Zebel et al., 2008), the correlational nature of our data does not allow for causal attributions. Thus, it could be relevant to manipulate animalistic and mechanistic dehumanization while removing extraneous stereotype content by considering fictitious outgroups (cf. Loughnan, Haslam, \& Kashima, 2009). Second, it is plausible that additional psychological mechanisms beyond empathy may be involved in the examined process. For instance, decreased perceptions of self-help (Stroebe \& Stroebe, 1996; Zagefka et al., 2011) could be a mediator of the relationship between animalistic dehumanization and willingness to help, since people who are seen as lacking HU are presumably judged as incompetent and disorganized, thus unable to improve their situation. Instead, increased attributions of victim blame (Campbell, Carr, \& MacLachlan, 2001; Zagefka et al., 2011) could explain the effects of mechanistic dehumanization: People who are seen as lacking $\mathrm{HN}$ are indeed judged less worthy of protection and more likely receive blame for their own behaviour (Bastian, Laham, Wilson, Haslam, \& Koval, 2011).

In conclusion, the current study has revealed an important intergroup bias at play in intergroup helping. Dehumanization reduces helping, although the type of dehumanization linked with this reduction critically depend on the group being considered. Some groups are not helped because these are tacitly viewed as animals, others because they are tacitly viewed as automata. This study also revealed lowered empathy as a likely mechanism via which dehumanization reduces peoples' willingness to help. Extraordinary disasters often mobilize us to help strangers, but it seems that humanitarian aid may be reserved for those we consider human.

\section{References}

Bain, P., Park, J., Kwok, C., \& Haslam, N. (2009). Attributing human uniqueness and human nature to cultural groups: Distinct forms of subtle dehumanization. Group Processes \& Intergroup Relations, 12, 789-805. doi:10.1177/1368430209340415

Bandura, A., Underwood, B., \& Fromson, M. E. (1975). Disinhibition of aggression through diffusion of responsibility and dehumanization of victims. Journal of Research in Personality, 9, 253269. doi:10.1016/0092-6566(75)90001-X

Bastian, B., \& Haslam, N. (2010). Excluded from humanity: The dehumanizing effects of social ostracism. Journal of Experimental Social Psychology, 46, 107-113. doi:10.1016/j.jesp.2009. 06.022

Bastian, B., Laham, S., Wilson, S., Haslam, N., \& Koval, P. (2011). Blaming, praising, and protecting our humanity: The implications of everyday dehumanization for judgments of moral status. British Journal of Social Psychology, 49, 469-483. doi:10.1348/014466610X521383

Batson, C. D. (1998). Altruism and prosocial behavior. In D. T. Gilbert, S. T. Fiske \& G. Lindzey (Eds.), The handbook of social psychology, Vol. II (pp. 282-316). New York, NY: McGraw-Hill.

Batson, C. D., \& Ahmad, N. (2001). Empathy-induced altruism in a prisoner's dilemma II: What if the target of empathy has defected? European Journal of Social Psychology, 31, 25-36. doi:10. 1002/ejsp. 26

Batson, C. D., Chang, J., Orr, R., \& Rowland, J. (2002). Empathy, attitudes, and action: Can feeling for a member of a stigmatized group motivate one to help the group? Personality and Social Psychology Bulletin, 28, 1656-1666. doi:10.1177/014616702237647

Brown, P. H., \& Minty, J. H. (2008). Media Coverage and Charitable Giving after the 2004 Tsunami. Southern Economic Journal, 75, 9-25. 
Campbell, D., Carr, S. C., \& MacLachlan, M. (2001). Attributing 'third world poverty' in Australia and Malawi: A case of donor bias? Journal of Applied Social Psychology, 31, 409-430. doi:10.1111/j. 1559-1816.2001.tb00203.x

Capozza, D., Andrighetto, L., Di Bernardo, G. A., \& Falvo, R. (2012). Does status affect intergroup perceptions of humanity? Group Processes E Intergroup Relations, 15, 363-377. doi:10.1177/ 1368430211426733

Čehajić, S., Brown, S., \& Gonzalez, R. (2009). What do I care? Perceived ingroup responsibility and dehumanization as predictors of empathy felt for the victim group. Group Processes \& Intergroup Relations, 12, 715-729. doi:10.1177/1368430209347727

Cheung, C. K., \& Chan, C. M. (2000). Social-cognitive factors of donating money to charity, with special attention to an international relief organization. Evaluation and Program Planning, 23, 241-253. doi:10.1016/\$0149-7189(00)00003-3

Cuddy, A. J. C., Rock, M. S., \& Norton, M. I. (2007). Aid in the aftermath of Hurricane Katrina: Inferences of secondary emotions and intergroup helping. Group Processes \& Intergroup Relations, 10, 107-118. doi:10.1177/1368430207071344

Dovidio, J. F., Piliavin, J. A., Schroeder, D. A., \& Penner, L. (2006). The social psychology of prosocial behavior. Mahwah, NJ: Lawrence Erlbaum.

Fisher, M. (2010, August 23). 4 reasons why Americans aren't giving for Pakistan flood relief. The Atlantic Monthly. Retrieved from http://www.theatlantic.com

Fiske, S. T., Cuddy, A. J. C., \& Glick, P. (2007). Universal dimensions of social cognition: Warmth and competence. Trends in Cognitive Sciences, 11, 77-83. doi:10.1016/j.tics.2006.11.005

Haddock, G., Zanna, M. P., \& Esses, V. M. (1993). Assessing the structure of prejudicial attitudes: The case of attitudes toward homosexuals. Journal of Personality and Social Psychology, 65, 11051118. doi:10.1037/0022-3514.65.6.1105

Haslam, N. (2006). Dehumanization: An integrative review. Personality and Social Psychology Review, 10, 252-264. doi:10.1207/s15327957pspr1003_4

Haslam, N., \& Bain, P. (2007). Humanizing the self: Moderators of the attribution of lesser humanness to others. Personality and Social Psychology Bulletin, 33, 57-68. doi:10.1177/ 0146167206293191

Haslam, N., Bain, P., Douge, L., Lee, M., \& Bastian, B. (2005). More human than you: Attributing humanness to self and others. Journal of Personality and Social Psychology, 89, 937-950. doi:10.1037/0022-3514.89.6.937

Haslam, N., \& Loughnan, S. (2014). Dehumanization and infrahumanization. Annual Review of Psychology, 65, 399-423. doi:10.1146/annurev-psych-010213-115045

Haslam, N., Loughnan, S., Kashima, Y., \& Bain, P. (2008). Attributing and denying humanness to others. European Review of Social Psychology, 19, 55-85. doi:10.1080/10463280801981645

Hayes, A. F. (2012). PROCESS: A versatile computational tool for observed variable mediation, moderation, and conditional process modeling. Retrieved from http://www.afhayes.com/ public/process2012.pdf

Hibbert, S., Smith, A., Davies, A., \& Ireland, F. (2007). Guilt appeals: Persuasion knowledge and charitable giving. Psychology and Marketing, 24, 723-742. doi:10.1002/mar.20181

Hopkins, N., Reicher, S., Harrison, K., Cassidy, C., Bull, R., \& Levine, M. (2007). Helping to improve the group stereotype: On the strategic dimension of prosocial behavior. Personality and Social Psychology Bulletin, 33, 776-788. doi:10.1177/0146167207301023

Kemmelmeier, M., Broadus, A. D., \& Padilla, J. B. (2008). Inter-group aggression in New Orleans in the immediate aftermath of Hurricane Kathrina. Analyses of Social Issues and Public Policy, 8 , 211-245. doi:10.1111/j.1530-2415.2008.00166.x

Knight, G. P., Johnson, L. G., Carlo, G., \& Eisenberg, N. (1994). A multiplicative model of the dispositional antecedents of a prosocial behavior: Predicting more of the people more of the time. Journal of Personality and Social Psychology, 66, 178-183. doi:10.1037/0022-3514.66.1. 178 
Leach, C. W., Iyer, A., \& Pedersen, A. (2007). Angry opposition to government redress: When the structurally advantaged perceive themselves as relative deprived. British Journal of Social Psychology, 46, 191-204. doi:10.1348/014466606X99360

Leidner, B., Castano, E., \& Ginges, J. (2013). Dehumanization, retributive and restorative justice, and aggressive versus diplomatic intergroup conflict resolution strategies. Personality and Social Psychology Bulletin, 39, 181-192. doi:10.1177/0146167212472208

Leidner, B., Castano, E., Zaiser, E., \& Giner-Sorolla, R. (2010). Ingroup glorification, moral disengagement, and justice in the context of collective violence. Personality and Social Psychology Bulletin, 36, 1115-1129. doi:10.1177/0146167210376391

Levine, M., Prosser, A., Evans, D., \& Reicher, S. (2005). Identity and emergency intervention: How social group membership and inclusiveness of group boundaries shape helping behavior. Personality and Social Psychology Bulletin, 31, 443-453. doi:10.1177/0146167204271651

Leyens, J.-Ph., Demoulin, S., Vaes, J., Gaunt, R., \& Paladino, M. P. (2007). Infrahumanization: The wall of group differences. Social Issues and Policy Review, 1, 139-172. doi:10.1111/j. 1751-2409.2007.00006.x

Loughnan, S., \& Haslam, N. (2007). Animals and androids: Implicit associations between social categories and nonhumans. Psychological Science, 18, 116-121. doi:10.1111/j.1467-9280. 2007.01858.x

Loughnan, S., Haslam, N., \& Kashima, Y. (2009). Understanding the relationship between attribute-based and metaphor-based dehumanization. Group Processes E Intergroup Relations, 12, 747-762. doi:10.1177/1368430209347726

Loughnan, S., Haslam, N., Sutton, R. M., \& Spencer, B. (2014). Dehumanization and social class; Animality in the stereotypes of "white trash", "Chavs", and "Bogans". Social Psychology, 45, 54 61. doi:10.1027/1864-9335/a000159

Loughnan, S., Pina, A., Vasquez, E. A., \& Puvia, E. (2013). Sexual objectification increases rape victim blame and decreases perceived suffering. Psychology of Women Quarterly, 34, 455-461. doi: $10.1177 / 0361684313485718$

Michel, L. M. (2007). Personal responsibility and volunteering after a natural disaster: The case of Hurricane Katrina. Sociological Spectrum, 27, 633-652. doi:10.1080/02732170701533855

Nadler, A. (2002). Inter-group helping relations as power relations: Maintaining or challenging social dominance between groups through helping. Journal of Social Issues, 58, 487-502. doi:10. $1111 / 1540-4560.00272$

Park, J., Haslam, N., Shimizu, H., Kashima, Y., \& Uchida, Y. (2013). More human than others, but not always better: The robustness of self-humanizing across cultures and interpersonal comparisons. Journal of Cross-Cultural Psychology, 44, 671-683. doi:10.1177/0022022113485429

Penner, L. A., Dovidio, J. F., Piliavin, J. A., \& Schroeder, D. A. (2005). Prosocial behavior: Multilevel perspectives. Annual Review of Psychology, 56, 365-392. doi:10.1146/annurev.psych.56. 091103.070141

Riva, P., \& Andrighetto, L. (2012). "Everybody feels a broken bone, but only we can feel a broken heart": Group membership influences the perception of targets' suffering. European Journal of Social Psychology, 42, 801-806. doi:10.1002/ejsp.1918

Saguy, T., Chernyak-Hai, L., Andrighetto, L., \& Bryson, J. (2013). When the powerful feels wronged: The legitimization effects of advantaged group members' sense of being accused for harboring racial or ethnic biases. European Journal of Social Psychology, 43, 292-298. doi:10.1002/ejsp. 1948

Saminaden, A., Loughnan, S., \& Haslam, N. (2010). Afterimages of savages: Implicit associations between "primitives", animals and children. British Journal of Social Psychology., 49, 91-105. doi:10.1348/014466609X415293

Stephan, W. G., \& Finlay, K. (1999). The role of empathy in improving intergroup relations. Journal of Social Issues, 55, 729-743. doi:10.1111/0022-4537.00144

Stroebe, W., \& Stroebe, M. (1996). The social psychology of social support. In E. T. Higgins \& A. W. Kruglanski (Eds.), Social psychology: Handbook of basic principles (pp. 597-621). New York, NY: Guilford. 
Sun, S., Zagefka, H., \& Goodwin, R. (2013). Predictors of intergroup concern for disaster victims of the Japan earthquake. Asian Journal of Social Psychology, 16, 152-157. doi:10.1111/ajsp. 12023

Vaes, J., Leyens, J.-Ph., Paladino, M. P., \& Miranda, M. P. (2012). We are human, they are not: Driving forces behind outgroup dehumanisation and the humanization of the ingroup. European Review of Social Psychology, 23, 64-106. doi:10.1080/10463283.2012.665250

Vaes, J., \& Paladino, M. P. (2010). The uniquely human content of stereotypes. Group Processes \& Intergroup Relations, 13, 23-39. doi:10.1177/1368430209347331

van Leeuwen, E. (2007). Restoring identity through outgroup helping: Beliefs about international aid in response to the December 2004 tsunami. European Journal of Social Psychology, 37, 661671. doi:10.1002/ejsp.389

van Leeuwen, E., \& Täuber, S. (2011). Demonstrating knowledge: The effects of group status on outgroup helping. Journal of Experimental Social Psychology, 47, 147-156. doi:10.1016/j. jesp.2010.09.008

Viki, G. T., Winchester, L., Titshall, L., Chisango, T., Pina, A., \& Russell, R. (2006). Beyond secondary emotions: The infrahumanization of outgroups using human-related and animal-related words. Social Cognition, 24, 753-775. doi:10.1521/soco.2006.24.6.753

Zagefka, H., Noor, M., Brown, R., de Moura, G. R., \& Hopthrow, T. (2011). Donating to disaster victims: Responses to natural and humanly caused events. European Journal of Social Psychology, 41, 353-363. doi:10.1002/ejsp.781

Zagefka, H., Noor, M., Brown, R., Hopthrow, T., \& de Moura, G. R. (2012). Eliciting donations to disaster victims: Psychological considerations. Asian Journal of Social Psychology, 15, 221230. doi:10.1111/j.1467-839X.2012.01378.x

Zebel, S., Zimmermann, A., Viki, G. T., \& Doosje, B. (2008). Dehumanization and guilt as distinct but related predictors of support for reparation policies. Political Psychology, 29, 193-219. doi:10. $1111 /$ j.1467-9221.2008.00623.x

Received 29 August 2013; revised version received 24 January 2014 